\title{
The influence of combined gradient structure with residual stress on crack-growth behavior in medium carbon steel
}

\author{
Yao Wang, ${ }^{\mathrm{a}, \mathrm{b}}$, Lichao Yuan ${ }^{\mathrm{a}, \mathrm{d}}$, Shijia Zhang, ${ }^{\mathrm{a}}$, Chengqi Sun ${ }^{\mathrm{a}}$, Wenjing Wang ${ }^{\mathrm{b}}$, \\ Guangxue Yang ${ }^{\mathrm{b}}$, Qiang $\mathrm{Li}^{\mathrm{b}, *}$, Yujie $\mathrm{Wei}^{\mathrm{a}, \mathrm{c}, *}$ \\ ${ }^{a}$ State Key Laboratory of Nonlinear Mechanics (LNM), Institute of Mechanics, Chinese Academy of Sciences, Beijing 100190, China \\ ${ }^{\mathrm{b}}$ Key Laboratory of Vehicle Advanced Manufacturing, Measuring and Control Technology, Ministry of Education, Beijing Jiaotong University, Beijing \\ 100044, China \\ ${ }^{\mathrm{c}}$ School of Engineering Sciences, University of Chinese Academy of Sciences, Beijing 100049, China \\ ${ }^{\mathrm{d}}$ School of Future Technology, University of Chinese Academy of Sciences, Beijing 100049, China
}

\section{A R T I C L E I N F O}

\section{Keywords:}

Gradient material

Residual stress

Fatigue crack

Cyclic J-integral

Crack- growth rate

\begin{abstract}
A B S T R A C T
Gradient materials produced by various external surface treatments are widely used in various mechanical structures. In this study, we illustrated how the combined gradient structure and residual stress influences crack-tip plasticity and crack-growth behavior in medium carbon steel S38C. The material used as train axles has a gradient layer of thickness about $8 \mathrm{~mm}$, with fine nanoscale structures in the surface to microstructures of tens of micron in the core. From the surface, the strength in the gradient layer decreases from about $1600 \mathrm{MPa}$ to about $400 \mathrm{MPa}$, and the corresponding tensile ductility increases from $2 \%$ to $13 \%$. Through in-situ fatigue tests, we further revealed slower crack-initiation and faster crack-growth rate in the gradient samples in contrast to their gradient-free coarse-grain counterparts. Using the key material parameters obtained from experiments, we employed finite-element simulations to examine the crack-growth behavior in the gradient structure with compressive residual stress. We showed that both the gradient structure and compressive residual stress reduce the plastic deformation size and hence slow down crack initiation. However, the lower ductility in the high strength gradient layer gives rise to even faster crack growth after the formation of a sharp crack. Based on the definition of the cyclic $\Delta J$-integral for small scale yielding, we saw lower $\Delta J$ in the presence of the residual stress distribution, hence smaller driving force for the crack-growth rate as the latter monotonically increases with $\Delta J$.
\end{abstract}

\section{Introduction}

More than $90 \%$ of metal engineering structures eventually fail due to fatigue [1,2]. Numerous studies have shown fatigue crack initiation often occurs on the surface of the material, and the fatigue strength is proportional to the tensile strength of the material $[3,4]$. An effective strategy to enhance the fatigue properties of engineering materials while at a relatively low expense is to introduce gradient structures where the material's structure and strength vary with the distance to the surface. Higher strength and finer structure in the surface layer often give rise to better fatigue and wear resistance of the materials. Such a strategy has been broadly

\footnotetext{
* Corresponding authors at: Key Laboratory of Vehicle Advanced Manufacturing, Measuring and Control Technology, Ministry of Education, Beijing Jiaotong University, Beijing 100044, China (Q. Li); State Key Laboratory of Nonlinear Mechanics (LNM), Institute of Mechanics, Chinese Academy of Sciences, Beijing 100190, China (Y. Wei).

E-mail addresses: qli3@bjtu.edu.cn (Q. Li), yujie_wei@lnm.imech.ac.cn (Y. Wei).
} 


\begin{tabular}{|c|c|c|c|}
\hline \multicolumn{2}{|c|}{ Nomenclature } & \multirow{2}{*}{$\begin{array}{l}f_{0} \\
\sigma_{t} \\
R\end{array}$} & \multirow{2}{*}{$\begin{array}{l}\text { initial void volume fraction } \\
\text { nominal stress } \\
\text { stress ratio }\end{array}$} \\
\hline$J$ & J-integral & & \\
\hline$\sigma$ & stress & $a$ & initial notch depth \\
\hline$\varepsilon$ & strain & $b$ & the thickness of TPB specimen \\
\hline$\sigma_{z z}$ & axial stress & $d$ & the width of TPB specimen \\
\hline$\sigma_{\theta \theta}$ & hoop stress & $L$ & the effective span of TPB specimen \\
\hline E & Young's modulus & $\varepsilon_{m}$ & mechanical strain \\
\hline$\frac{d a}{d N}$ & crack-growth rate & $\varepsilon_{i}$ & initial strain \\
\hline $\begin{array}{l}d N \\
m\end{array}$ & exponent in the Paris law & $\lambda(s)$ & virtual crack path \\
\hline$A^{\prime}$ & coefficient in the Paris law & $W$ & strain energy density \\
\hline$\Delta k$ & stress intensity factor & $\Delta J_{p a t h}$ & the change of the $J$-integral within a load cycle \\
\hline$\sigma_{0}$ & yield strength & $C$ & material constants \\
\hline$\sigma_{u t s}$ & ultimate strength & $n^{\prime}$ & material constants \\
\hline$\varepsilon_{\text {uni.max }}$ & maximum uniform strain & $K_{\max }$ & the maximum stress intensity factor \\
\hline$\Phi$ & plastic potential & $K_{\min }$ & the minimum stress intensity factor \\
\hline $\bar{\sigma}$ & von Mises stress & $J_{\max }$ & J-integral for the maximum nominal stress \\
\hline $\bar{\varepsilon}$ & equivalent strain & $J_{\min }$ & J-integral for the minimum nominal stress \\
\hline$\sigma_{m}$ & $\begin{array}{l}\text { hydrostatic tension of a representative volume } \\
\text { element }\end{array}$ & $\begin{array}{l}S M G T \\
\text { SMAT }\end{array}$ & $\begin{array}{l}\text { surface mechanical grinding treatment } \\
\text { surface mechanical attrition treatment }\end{array}$ \\
\hline$q_{1}, q_{2}, q_{3}$ & $\begin{array}{l}\text { parameters of Gurson-Tvergaard-Needleman } \\
\text { model }\end{array}$ & $\begin{array}{l}G N G \\
C G\end{array}$ & $\begin{array}{l}\text { gradient nano-grained } \\
\text { coarse-grained }\end{array}$ \\
\hline$f$ & void volume fraction & $T W I P$ & twinning-induced plasticity \\
\hline$\dot{f}$ & void growth rate & $L C F$ & low-cycle fatigue \\
\hline$\dot{\boldsymbol{\varepsilon}}^{p l}$ & plastic strain rate tensor & $H C F$ & high-cycle fatigue \\
\hline I & unit tensor & FEM & finite element method \\
\hline$\dot{\bar{\varepsilon}}^{p l}$ & equivalent plastic strain rate & $2 D$ & two-dimensional \\
\hline $\bar{\varepsilon}^{p l}$ & equivalent plastic strain & $3 D$ & three-dimensional \\
\hline$v$ & the Poisson's ratio & $W E D M$ & wire electric discharge machining \\
\hline$\varepsilon_{N}$ & $\begin{array}{l}\text { the mean of the normal distribution for nucleation } \\
\text { strain }\end{array}$ & $\begin{array}{l}S E M \\
T P B\end{array}$ & $\begin{array}{l}\text { scanning electron microscope } \\
\text { three point bending }\end{array}$ \\
\hline $\begin{array}{l}S_{N} \\
f_{N}\end{array}$ & $\begin{array}{l}\text { the standard deviation of the normal distribution } \\
\text { volume fraction of the nucleated voids }\end{array}$ & GTN & del Gurson-Tvergaard-Needleman model \\
\hline
\end{tabular}

seen in engineering materials and indeed was inspired by gradient structures in natural materials of extraordinary properties [5-8]. In the past decades, researchers have been exploring the methods to build gradient structures in engineering material. Several treatments [9-12] -including surface induction, shot peening [13], heat treatment, mechanical grinding [14] and attrition [15], predeformation [16], were used to produce gradient layers of thickness from several hundreds of nanometers to several millimeters. Materials with surface gradient layers can effectively minimize the probability of surface failure initiation and therefore result in much better fatigue performance.

So far, a vast amount of experimental study have shown that gradient structures have a positive effect on various mechanical properties of materials, such as high strength and ductility retention [16-25], better resistance of fatigue [26-32] and better wear resistance [33,34] et al. By using the surface mechanical grinding treatment (SMGT) method for microstructure construction, Lu and Fang et al. $[18,19]$ prepared a gradient nano-grained (GNG) Cu film with spatial grain-size gradient on a coarse-grained (CG) Cu substrate. The samples exhibited much higher yield strength to that of CG counterpart but without compromising its ductility. Such extraordinary strength-ductility performances above also appeared in the samples prepared by surface mechanical attrition treatment (SMAT) on stainless steel by Chan et al. [20]. By employing a simple method called pre-torsion on twinning-induced plasticity (TWIP) steel and 304 austenitic steel, Wei et al. [16] demonstrated that a linearly gradient twin density material could be introduced and used to evade the long-standing dilemma of strength-ductility trade-off commonly seen in steels. Ma et al. [21] used pre-torsion samples to reveal that the spatial twin density gradient could effectively enhance the fatigue resistance of 304 austenitic stainless steel. Zhang et al. [27] introduced the common surface treatment called shot peening on high-strength wrought magnesium alloy AZ80 and reported that the fatigue strength of AZ80 improved significantly: an increase of $60 \%$ in the fatigue limit was obtained at the optimum condition. Yang et al. [28] further studied the fatigue performance of GNG/CG Cu samples prepared by SMGT method, and the authors demonstrated that the gradient exhibited a greatly enhanced fatigue limit under stress-controlled cyclic deformation, and suppressed the nucleation effect of crack. By introducing the gradient structure by SMAT method, Roland et al. [29] revealed that the gradient structure led to a great lifetime improvement in the fatigue limit in the region of low-cycle fatigue (LCF) and this became even more pronounced at high-cycle fatigue (HCF).

The mechanisms how the unique gradient microstructures lead to the extraordinary mechanical properties have been studied in detai [34-38]. In gradient samples prepared by SMAT, Wu et al. [34] reported a strain hardening mechanism that is inherent to gradient structure and does not exist in homogeneous material to achieve the high ductility of materials. By applying the in-situ 
synchrotron radiation experiments, Ma et al. [35] explored the phase-transformation and stress distribution of pre-twisted 304 austenitic stainless steel samples at the cryogenic temperature of $77 \mathrm{~K}$. It was revealed that a graded mixture of hard martensitic and soft austenitic phases resulted in an optimal stress partition in the material. Zeng et al. [36] used a crystal plasticity constitutive model based on the finite-element method (FEM) to understand the plastic deformation distribution with two-dimensional (2D) sample during the small deformation process. Furthermore, Wang et al. [37] employed a representative three-dimensional (3D) Voronoi FEM gradient sample to demonstrate the redistribution of stress and deformation in the gradient structure during the large deformation process. Their simulations elegantly revealed the presence of strain gradient in gradient samples, in good consistent with the experimental observations by $\mathrm{Wu}$ et al. [34].

Literature mentioned before demonstrated that gradient structure could effectively improve the strength-ductility combination and also significantly increased the fatigue limit of the materials. Although crack-growth behavior is also important for fatigue fracture, many studies have shown that the grain refinement is not always beneficial to the crack-growth behavior [2,39-41]. Yin et al. [39] and Trudel et al. [40] performed a series of experiments on 2524 aluminum alloy and stainless steel and found fatigue crack-growth rate in the fine-grained region was faster than that in the coarse grain region. Moreover, the presence of gradient structured material by the surface treatment method often gives rise to residual stress. Such residual stress also plays a significant role in affecting the fatigue endurance of surface strengthened materials [42-47]. Many literatures [48-51] have shown that the residual compressive stress resulted from surface mechanical treatment could effectively improve the fatigue resistance. More recently, Zhang et al. [52] studied experimentally the fatigue crack-growth behavior in gradient axle steel with residual stress. The authors reported crack arrest in the gradient layer under relatively low stress amplitude, which was a resultant of compressive residual stress. The coupling between residual stress and gradient structure renders the traditional theory of fatigue crack-growth behavior no longer applicable. The theoretical study of crack-growth behavior in surface strengthened materials is still challenging that requires in-depth investigation. Motivated by the aforementioned factors, in this paper, we reported a finite-element based mechanism analysis to show the influence of combined residual stress and gradient structure on crack-growth behavior in medium carbon steel.

\section{Experimental investigation}

\subsection{Material and specimen}

The material investigated in our study is a medium carbon steel S38C obtained from a high-speed train axle. The chemical composition of the material is tabulated in Table 1. Surface induction hardening was used. The processed steel owes a gradient structural in the surface layer.

To obtain the mechanical property in the gradient layer, we cut small-scale tensile specimens from the surface layer along the radial direction using wire electric discharge machining (WEDM). We show in Fig. 1(a) how the samples were prepared. The gradient layer has a thickness of $8.00 \mathrm{~mm}$. We prepared eight samples along the radial direction in the gradient layer, which each small-scale specimen about $1 \mathrm{~mm}$ in thickness, and other dimensions are also given in Fig. 1(b). We further mirror-polished the specimens by using the water sandpapers from 150 grade to 5000 grade and the diamond polisher, in order to eliminate the effect of WEDM to the surfaces.

\subsection{Microhardness}

The cross-section of a processed S38C steel cylinder was used for microhardness characterization. We used the Vickers microhardness tester MH-6. For the validity of measurement, we carried out five independent tests for a given depth from the surface. Along the radial direction, neighboring indentations had a distance of $0.30 \mathrm{~mm}$, which is significantly greater than the indenter size of $20 \mu \mathrm{m}$. The applied load was $300 \mathrm{~g}$ with a dwell time of $10 \mathrm{~s}$ at room temperature. We show in Fig. 1(c) the microhardness of the sample from the surface with a depth of $0.05 \mathrm{~mm}$ to $8.05 \mathrm{~mm}$, which covers the gradient microstructures. The error bar represents the standard deviation of five measurements at each depth. There is a hardness plateau in the gradient layer within a depth from $0.05 \mathrm{~mm}$ to $2.05 \mathrm{~mm}$ when measured from the surface; the microhardness remains at the maximum of $580 \mathrm{Hv}$ within this regime. It then decreases within a thin layer and is about $200 \mathrm{Hv}$ at the depth of $6.06 \mathrm{~mm}$. At the depth of $8.00 \mathrm{~mm}$, the microhardness is the same as that of the core material, as one would expect.

\subsection{Microstructure}

We used optical microscopy to examine the cross-section microstructure and to see how it evolves from the surface to the core. In Fig. 2, we first present the observation path. The corresponding microstructures at a depth keyed in the observation path, as shown in Fig. 2(a)-(i). From the gradient microstructure of the S38C axle steel processed by surface induction hardening, we see typical

Table 1

Chemical composition of steel S38C.

\begin{tabular}{|c|c|c|c|c|c|c|c|c|c|}
\hline Element & $\mathrm{C}$ & $\mathrm{Si}$ & $\mathrm{Mn}$ & $\mathrm{N}$ & $\mathrm{O}$ & S & $\mathrm{P}$ & $\mathrm{Al}$ & $\mathrm{Fe}$ \\
\hline wt.\% & 0.39 & 0.32 & 0.84 & 0.0041 & 0.0006 & 0.0084 & 0.0072 & 0.02 & Balance \\
\hline
\end{tabular}


(a)

(b)

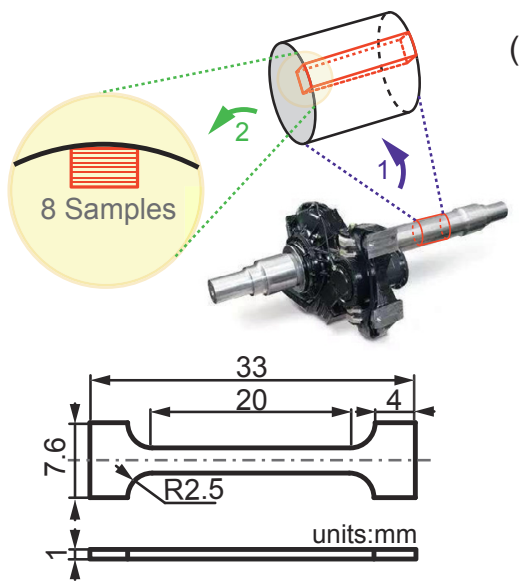

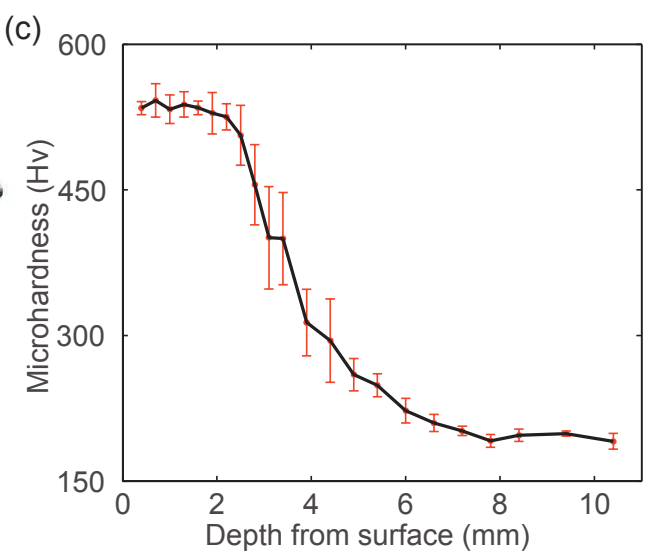

Fig. 1. The hardness of gradient axial steel. (a) Small-scale tensile samples cut from a gradient axle. (b) Dimensions of the sample. (c) The microhardness as a function of depth from the surface. The error bar of microhardness at each depth represents the standard deviation of five independent tests.

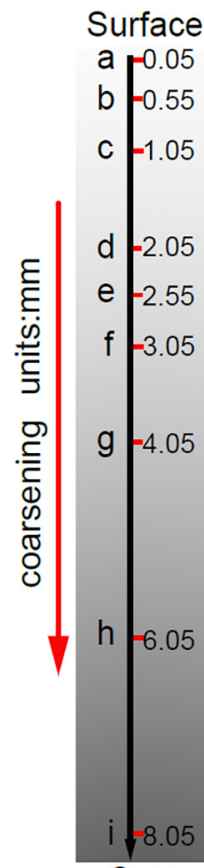

Core
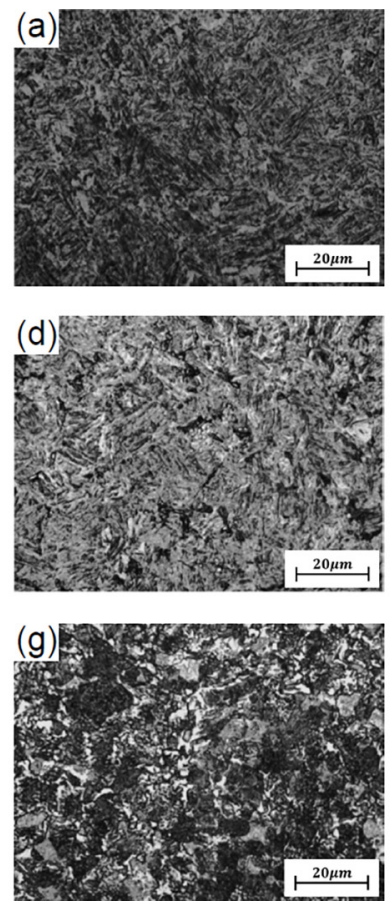
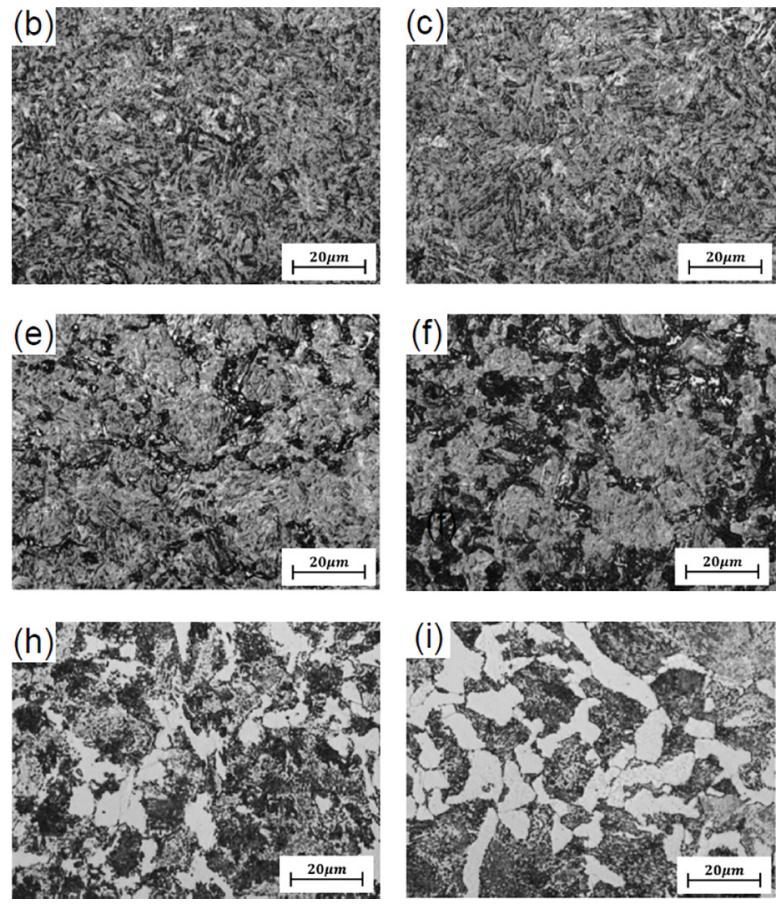

Fig. 2. Microstructure at different depths from the surface of the gradient axle steel S38C. (a) to (i) are the microstructure characteristics based on an optical microscope with the depth of $0.05 \mathrm{~mm}, 0.55 \mathrm{~mm}, 1.05 \mathrm{~mm}, 2.05 \mathrm{~mm}, 2.55 \mathrm{~mm}, 3.05 \mathrm{~mm}, 4.05 \mathrm{~mm}, 6.05 \mathrm{~mm}$ and $8.05 \mathrm{~mm}$, respectively.

tempered martensite structure at the location just beneath the surface (about $0.05 \mathrm{~mm}$ from the surface, Fig. 2(a)-(c)). At the depth of $2.05 \mathrm{~mm}$ from the specimen surface, a small amount of fine pearlite structure appears in the tempered martensite structure. Comparing with Fig. 1(c), we see the hardness begins to drop rapidly from this depth. Then the small domains of pearlite and ferrite gradually appear within the tempered martensite colonies from the depth of $2.05 \mathrm{~mm}$ to $4.05 \mathrm{~mm}$, as demonstrated in Fig. 2(d)-(g). As the depth increases to about $4.05 \mathrm{~mm}$ to $6.05 \mathrm{~mm}$, the microstructure is a mixture of pearlite, ferrite and distributed quenchedtempered microstructure, see Fig. 2(h). At the depth of $8.05 \mathrm{~mm}$, the material is composed of coarse ferrite and pearlite (Fig. 2(i)), which is the same microstructure as that in the as-received materials.

\subsection{Residual stress}

Commonly, residual stress appears as a resultant of the formation of gradient structures. In the cylindrical sample, two residual stress components are of significance, the axial stress $\sigma_{z z}$ and the hoop stress along the circumferential direction $\sigma_{\theta \theta}$. As the axial stress 
is perpendicular to potential crack planes with normal parallel to the axial direction and is the most dangerous scenario for the axles subject to bending, we will focus on the influence of the residual stress in the axial direction. Unless stated otherwise, we refer residual stress as $\sigma_{z z}$ in what follows. The axial residual stress of a train axle was measured along the gradient direction from the surface to the core by a Proto X-Ray stress analyzer with $\mathrm{Cr}$-K $\alpha$ radiation. Similar to the microhardness measurement, we performed five independent tests to obtain accurate residual stress at each depth, and the averaged value is used to represent the residual stress at that depth, as we see in Fig. 3. The error bar represents the standard deviation of residual stress from five independent tests. The maximum compressive residual stress occurs at the depth between $1.5 \mathrm{~mm}$ and $2.5 \mathrm{~mm}$ from the surface. It then decreases to zero and becomes tensile afterwards, in order to maintain the overall force balance along the axial direction.

\subsection{Uniaxial tension}

The stress-strain behavior of materials in the gradient layer was characterized by using small-scale tests. The corresponding sample dimensions are shown in Fig. 1(b). Tensile tests were carried out at a tensile strain rate of $10^{-3} \mathrm{~s}^{-1}$ at room temperature. Each sample has a thickness of $1 \mathrm{~mm}$, and its mechanical properties represent those of the material at that depth. Using this approach, the uniaxial tensile properties of the layered samples at the depth of $0.50 \mathrm{~mm}, 1.50 \mathrm{~mm}, 2.50 \mathrm{~mm}, 3.50 \mathrm{~mm}, 4.50 \mathrm{~mm}, 5.50 \mathrm{~mm}$, $6.50 \mathrm{~mm}$, and $7.50 \mathrm{~mm}$ were obtained. To ensure repeatability, we tested five samples at each depth in the gradient layer. In Fig. 4(a)-(c), we show respectively the stress- strain curves from five independent tests at each depth of $0.5 \mathrm{~mm}, 4.5 \mathrm{~mm}$, and $6.5 \mathrm{~mm}$. The average of the five stress-strain curves at each depth is taken as the representative stress-strain behavior of the material at that depth. The stress-strain response of the material shown in Fig. 4(d) reflects the traditional dilemma between the strength and ductility of the material in the gradient layer, i.e. as the strength of material increases, the ductility gradually decreases [19-20,36]. Combining the $\sigma_{u t s}$ (ultimate strength) from stress-strain curves of the uniaxial tensile test with the microhardness test results of the gradient structure, it is seen that the value of $\sigma_{b}$ is about three times of the microhardness using the unit of $H v$.

\subsection{In-situ SEM fatigue test}

With the help of in-situ scanning electron microscopy (SEM) fatigue test, we investigated the fatigue crack initiation and growth behavior in the gradient structural S38C steel by using a pre-notched sample at room temperature. The in-situ fatigue test machine was attached to an SEM (SS-550) with electro-hydraulic servo system. We conducted the in-situ SEM fatigue test in a vacuum environment with a loading frequency of $10 \mathrm{~Hz}$ and load amplitude of $620 \mathrm{MPa}$ at load ratio $R=0.1$. A typical notched specimen (as shown in Fig. 5(a)) was prepared using the surface gradient material or the gradient-free base material. It is worth noting that since the thickness of the sample is only $2 \mathrm{~mm}$ in the radial direction of the axle, the influence of the residual stress is negligible as the current sample preparation method may lead to stress relaxation.

The surface of the two types of samples after polishing and etching are shown in Fig. 5(b) and (c). From the results of fatigue crack initiation shown in Fig. 5(d) and (e), we see that the gradient (surface) material has better resistance to crack initiation than the gradient free (core) material. This observation is consistent with previous reports [1,27-31]: the gradient layer is effective in improving the fatigue life during crack initiation, mainly because of the general correlation between yielding strength and fatigue limit [3]. It differs from the delayed shear band nucleation in dynamic process [1] as no localized shearing was observed in those fatigued samples. The fatigue crack-growth rate curves shown in Fig. 5(f) further imply the disadvantage of resistance to crack growth in this particular material. Using the Paris law for fatigue growth [53,54], $\frac{d a}{d N}=A^{\prime}(\Delta k)^{m}$, we have $m=3.58$ for the base material and $m=2.09$ for the surface material. While the absolute crack growth rate $\frac{d a}{d N}$ in the surface material is faster than that of the base material, the power-law exponent $m$ of the surface material is perceivably smaller than that of the base material. As reported in a

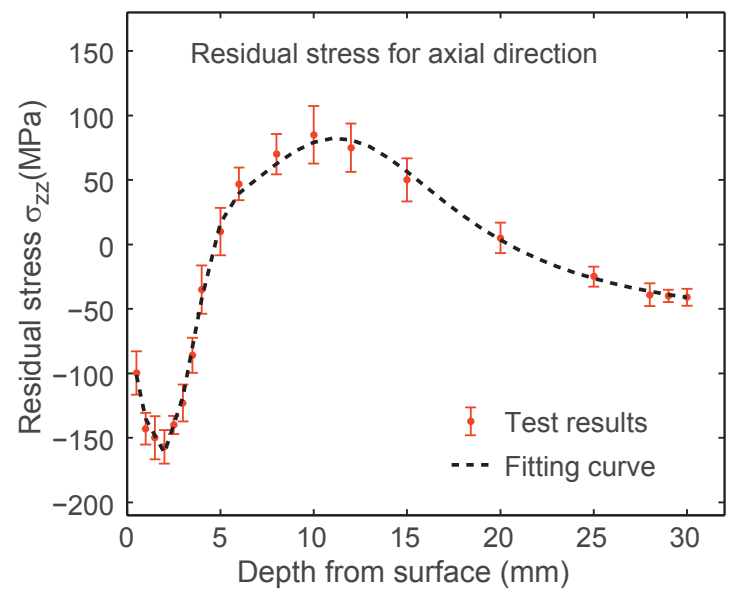

Fig. 3. The residual stress distribution in the axial direction in gradient steel. The dashed line is its fitting curve. The error bar represents the standard deviation of residual stress from five independent tests. 

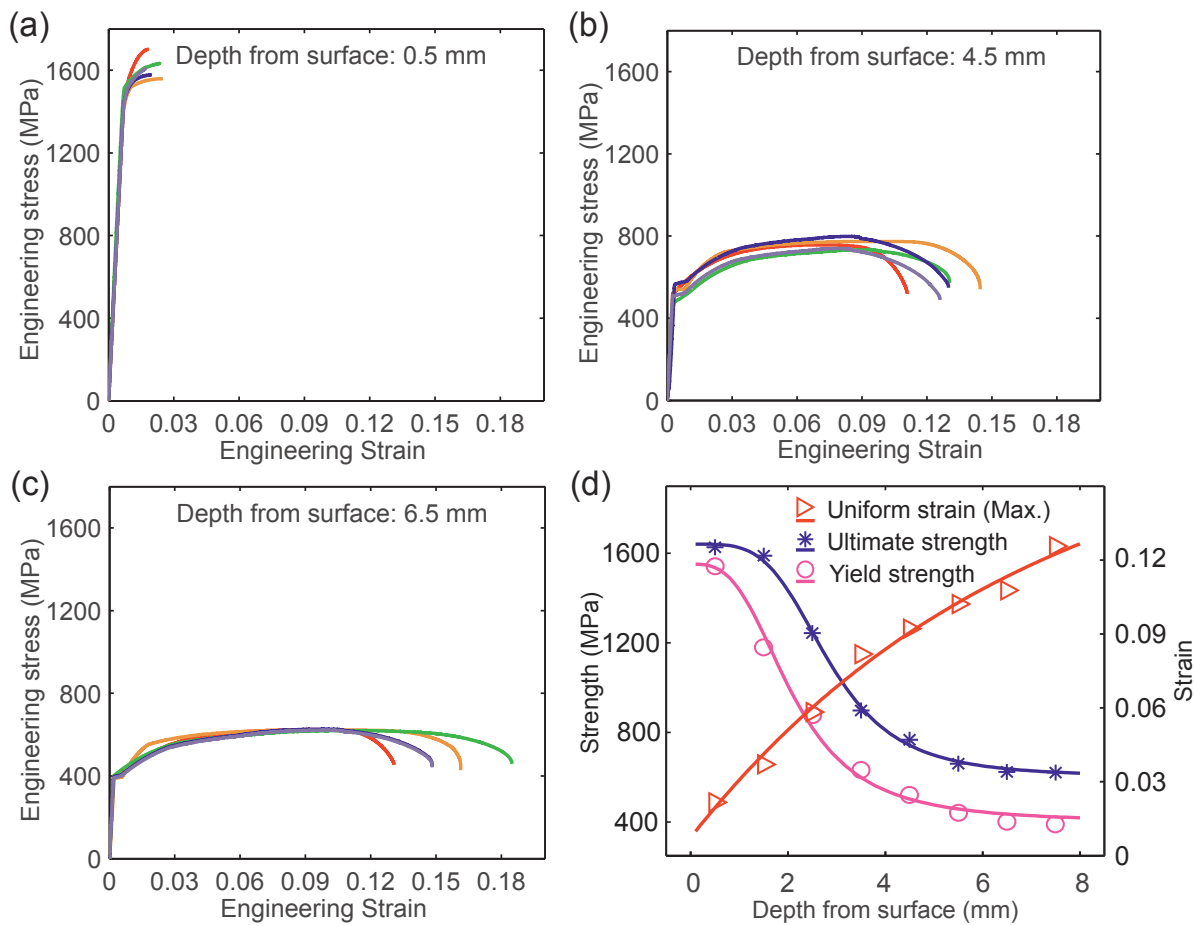

Fig. 4. Stress-strain behavior of materials at different depth in the gradient axle. (a)-(c) Stress-strain curves of five independent tests at each depth from the surface: (a) $0.5 \mathrm{~mm}$, (b) $4.5 \mathrm{~mm}$, and (c) $6.5 \mathrm{~mm}$, respectively. (d) Average yielding/ultimate strength and the corresponding uniform strain (max.) as function of depth and their corresponding functional fitting curves.
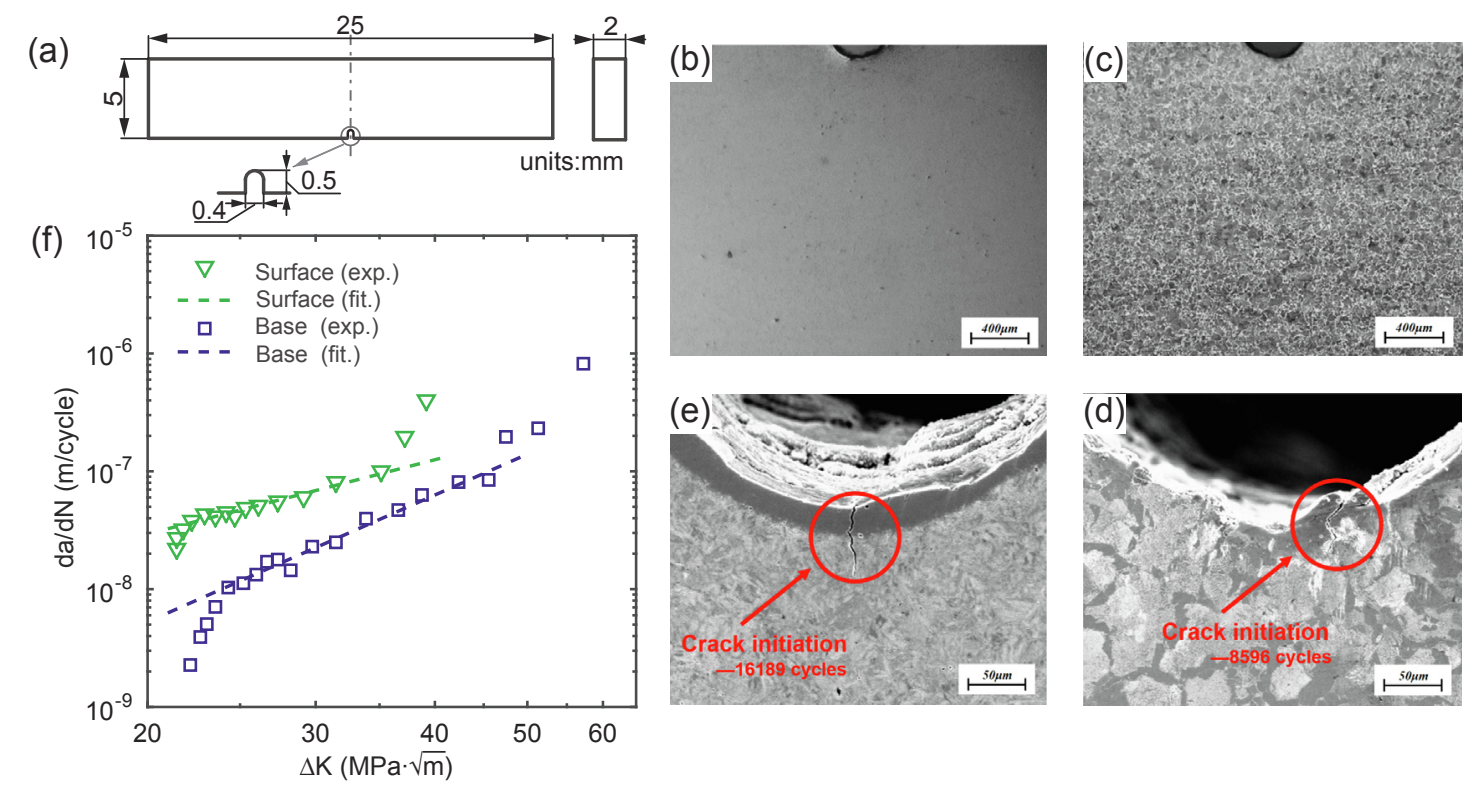

Fig. 5. In-situ SEM fatigue test of gradient samples. (a) Dimensions of the in-situ SEM fatigue test specimen. (b) and (c) the optical microstructure observation of two polish-etched samples with different depths for three points bending (TPB) tests, in turn, the surface layer and the core layer, respectively. (e) and (d) the SEM images for the initiation of a fatigue crack, corresponding to (b) and (c), respectively. (f) $d a / d N$ versus $\Delta k$ curves of surface material and base (core) material.

large number of literatures [39-41], the fatigue crack-growth rate of the surface material is significantly higher than that of the base (core) material due to its poor plasticity and intergranular defects. The above in-situ SEM fatigue test results demonstrate that simply introducing a gradient structure cannot guarantee an overall improvement of the fatigue life of the material. 


\section{Numerical modelling}

In the designed experiments, the role played by residual stress in the gradient layer is not considered. We resort to numerical modeling to investigate the influence of the gradient layer and the additional residual stress on the fatigue behavior of the axle steel S38C. We conducted a series of 2D plane strain numerical tests to illustrate the combined mechanisms.

In order to obtain accurate physical characteristics in the gradient material, we first calibrated the material parameters used for the finite-element model. For convenience, we adopted the Ramberg-Osgood relationship and the Gurson-Tvergaard-Needleman (GTN) model to describe the hardening and softening behaviors of multi-layered material. The major part of the method and its technical detail have been reported elsewhere [55-60]. Here, we briefly introduce the strategies of the Ramberg-Osgood relationship and the GTN model embedded in ABAQUS [61]:

The Ramberg-Osgood relationship is created to describe non-linear behavior between the stress and strain. Such a relationship is especially useful for metallic materials that hardening with plastic deformation, showing a smooth elastic-plastic transition [55]. In the last form of the Ramberg-Osgood relationship, it could be written as:

$$
\varepsilon=\frac{\sigma}{E}+\alpha \frac{\sigma}{E}\left(\frac{\sigma}{\sigma_{0}}\right)^{n-1}
$$

where $\varepsilon, \sigma, \sigma_{0}, E, n$ are strain, stress, yield strength, Young's modulus and the power-law exponent, respectively. Here $\alpha \frac{\sigma}{E}$ can be regarded as a yield offset. It can be fixed in order to have the yield offset equal to the accepted value of strain of $0.2 \%$, which means: $\alpha \frac{\sigma}{E}=0.002$. We show in Table 2 the material parameters at different depth from the uniaxial tensile tests (as shown in Fig. 6(c)). The remaining material parameters of other layers in our simulations were also extracted by fitting Eqn. (1) to real stress-strain curves. By combing the experimental data and the Ramberg-Osgood relationship, we can effectively capture the hardening behavior of each individual layer in the gradient region.

In polycrystalline metals, ductile fracture is controlled by nucleation, growth of microvoids and coalescence of microvoids [63]. The best known micro-mechanical model for void related damage and fracture is due to Gurson [56]. Thereafter, some important modifications are due to Tvergaard [57-59] who introduced adjustment parameters and to Needleman and Chu [60] who proposed improved nucleation laws for porosity. For such aforementioned reasons, the model is called for GTN model. The plastic potential in the GTN model $[61,62]$ is given as

$$
\Phi=\left(\frac{\bar{\sigma}}{\sigma_{0}}\right)^{2}+2 q_{1} f \cosh \left(\frac{3 q_{2} \sigma_{m}}{2 \sigma_{0}}\right)-1-q_{3} f^{2}
$$

where $\bar{\sigma}$ and $\sigma_{m}$ are the effective (von Mises) stress and the hydrostatic tension of a representative volume element, $\sigma_{0}$ is the initial yielding strength of the material, $q_{1}, q_{2}$ and $q_{3}$ are the material-dependent correction parameters. The void volume fraction $f$ starts from an initial volume fraction $f_{0}$ and evolves in the following manner:

$$
\dot{f}=(1-f) \dot{\boldsymbol{\varepsilon}}^{p l}: \mathbf{I}+\frac{\dot{\bar{\varepsilon}}^{p l} f_{N}}{\sqrt{2 \pi} s_{N}} \exp \left[-\frac{1}{2}\left(\frac{\bar{\varepsilon}^{p l}-\varepsilon_{N}}{s_{N}}\right)^{2}\right]
$$

where $\dot{\varepsilon}^{p l}$ is the of plastic strain rate tensor and $\mathbf{I}$ is the unit tensor, and $\dot{\varepsilon}^{p l}$ is the equivalent plastic strain rate, $\dot{\bar{\varepsilon}}^{p l}=\sqrt{2 / 3\left[\operatorname{dev}\left(\dot{\varepsilon}^{p l}\right): \operatorname{dev}\left(\dot{\boldsymbol{\varepsilon}}^{p l}\right)\right]}$, and $\bar{\varepsilon}^{p l}=\int_{0}^{t} \dot{\bar{\varepsilon}}^{p l} d t$. Here $f_{N}, \varepsilon_{N}$ and $s_{N}$ are material parameters associated with void nucleation rate. For the application of the GTN model embedded in ABAQUS to capture the softening behavior of multi-layered structure material, in our study, we assume that the initial void parameters of multilayer materials are uniform and do not change as the surface hardening process going on.

For the application of the Ramberg-Osgood relationship and the GTN model embedded in ABAQUS, we need to specify the elastic and the plastic behavior of multi-layered gradient material, respectively. Here, we used $E=209.40 \mathrm{GPa}$ and $\nu=0.30$ as the elastic parameters for the multi-layered FEM model.

By using the functional fitting curves based on the key data of uniaxial tensile test (as shown in Fig. 4(d)) as the plastic parameters, we are able to capture the tensile behavior of each layer of material from the multi-layered structure, including the failure

Table 2

\begin{tabular}{|c|c|c|c|c|}
\hline $\operatorname{Depth}(\mathrm{mm})$ & $\sigma_{0}(M P a)$ & $\sigma_{u t s}(M P a)$ & $\varepsilon_{\text {uni.max. }}$ & $n$ \\
\hline 0.5 & 1536.24 & 1640.31 & 0.0195 & 27.92 \\
\hline 1.5 & 1238.10 & 1565.47 & 0.0413 & 13.05 \\
\hline 2.5 & 821.06 & 1248.56 & 0.0601 & 8.87 \\
\hline 3.5 & 599.44 & 913.73 & 0.0764 & 9.50 \\
\hline 4.5 & 502.87 & 742.82 & 0.0906 & 10.67 \\
\hline 5.5 & 458.31 & 670.16 & 0.1028 & 11.28 \\
\hline 6.5 & 435.67 & 638.05 & 0.1133 & 11.51 \\
\hline 7.5 & 423.14 & 622.61 & 0.1225 & 11.59 \\
\hline
\end{tabular}

Material parameters of the multi-layered model in simulations, which were obtained by fitting Eqn. (1) to the tested stress-strain curves at different depth. 

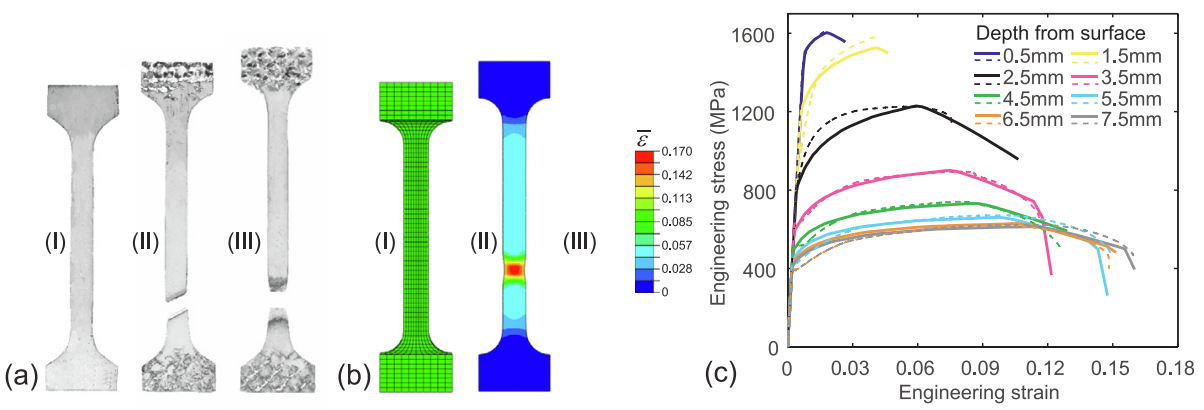

Fig. 6. Material parameter calibration of samples at different depth. (a) The representative results of uniaxial tensile tests with layered samples of gradient material, from (I) to (III), in turn, the initial sample, the failed material at the depth of $0.5 \mathrm{~mm}$ and the failed one at the depth of $7.5 \mathrm{~mm}$, respectively. (b) The constitutive model validation with the finite-element method for the base material (the equivalent plastic strain $\bar{\varepsilon}$ contours): (I) to (III), in turn, the initial meshed sample, necking, and final failure, respectively. (c) The stress-strain curves from both experimental measurement (dashed line) and that from our finite-element simulation (solid) using the constitute model.

point. Other material parameters of GTN model are tabulated in Table 3. A series of FEM simulations are conducted, through which the material parameters are fitted to obtain the tensile stress-strain curves of materials at different depth, and those curves match well with corresponding experimental measurements, as illustrated in Fig. 6. We show in Fig. 6(a) the tested samples after uniaxial tension: brittle fracture of the strong one with poor plasticity (the material at the depth of $0.5 \mathrm{~mm}$ ) against ductile fracture of the core material with good plasticity (the material at depth of $7.5 \mathrm{~mm}$ ). Our simulations shown in Fig. 6(b) predict the premature failure in the strong and brittle surface layer and intermediate plasticity in the core material. Fig. 6(c) shows the stress-strain behavior of a representative set of layered specimens under uniaxial tensile numerical test. All these stress-strain curves indicate that the numerical results have a good consistency with test results.

We present in Fig. 7 the fatigue model used in our numerical simulations. To present the gradient layer, we discretize the region of interest (within a depth of $8.00 \mathrm{~mm}$ from the surface) into 40 layers along the gradient direction and mesh that region with fine element size (about $0.01 \mathrm{~mm}$ ). The rest information of numerical model is shown in Fig. 7 . Then by applying the results from the fitting curves using the Ramberg-Osgood relationship and the GTN model, we assign the mechanical properties in each layer based on its distance from the surface. In the presence of residual stress, we assign the residual stress to different layers based on the predefined normal stress distribution in the z-direction of cylindrical coordinate, as seen in Fig. 3.

The bending simulations are applied using the load-controlled method. With the geometrical parameters defined in Fig. 7, the amplitude of the nominal stress in the notched plane is then written as

$$
\sigma_{t}=\frac{3 F L}{2 b(d-a)^{2}}
$$

where, $\sigma_{t}$ is the loading nominal stress. In our numerical investigation, the stress ration is set to $R=0.1$. We use two nominal stresses $\sigma_{t}=320 \mathrm{MPa}$ and 480MPa. With $a=0.5 \mathrm{~mm}, b=1 \mathrm{~mm}$ (unit thickness), $d=30 \mathrm{~mm}$ and $L=120 \mathrm{~mm}$ given in Fig. 7, it is convenient to obtain the applied force $F$ of $1547 \mathrm{~N}$ and $2320 \mathrm{~N}$, respectively.

\section{Simulation results}

Three different types of samples were considered in our simulations, including the base material (material in the core) without gradient, the gradient structure without residual stress, and the gradient structure with residual stress. The crack length was measured from the surface by taking the notch depth of $0.5 \mathrm{~mm}$ into account.

The contours of the principal stress in z-direction $\sigma_{z z}$, von Mises stress $\bar{\sigma}$ and equivalent plastic strain $\bar{\varepsilon}$ at different crack length are presented in Figs. 8 and 9, with $\sigma_{t}=320 \mathrm{MPa}$ and $480 \mathrm{MPa}$, respectively. For the convenience of comparison, we show in Fig. 8(a), (d) and (g) the contours of $\sigma_{z z}, \bar{\sigma}$ and $\bar{\varepsilon}$ of the gradient-free base materials. The corresponding contours of the gradient material are presented in Fig. 8(b), (e) and (h). Due to the presence of gradient structure, $\sigma_{z z}$ and $\bar{\sigma}$ in the crack tip become more uniform, as clearly seen in Fig. 8(b), (e). During the entire crack growth process, the plastic zone of the specimen with a gradient structure is significantly smaller than the one with the homogeneous base material (see Fig. 8(g)-(h)). Such a positive influence of gradient structure is analogous to that reported in experimental observation [64]. When residual stress is taken into account, we see the corresponding three contours of $\sigma_{z z}, \bar{\sigma}$ and $\bar{\varepsilon}$ shown in turn in Fig. 8(c), (f) and (i) are distinct from those of the base material and the

Table 3

Material parameters used in the GTN model to capture the softening behavior of materials in the gradient layer.

\begin{tabular}{lllllll}
\hline$q_{1}$ & $q_{2}$ & $q_{3}$ & $\varepsilon_{N}$ & $S_{N}$ & $f_{N}$ & $f_{0}$ \\
\hline 1.5 & 1 & 2.25 & 0.3 & 0.1 & 0.003 & 0.002 \\
\hline
\end{tabular}




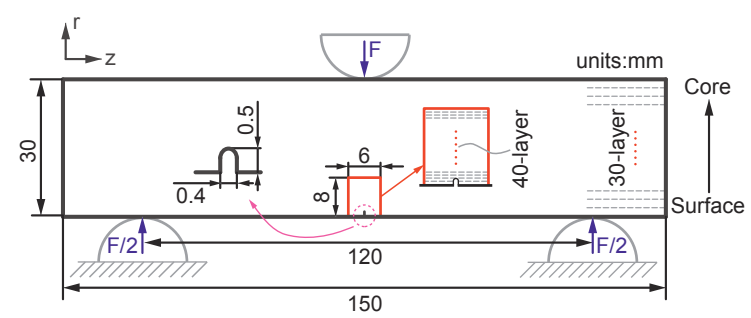

Fig. 7. The finite-element model to capture the gradient structure of the axle steel used for fatigue test. The region in front of the initial notch is partitioned into 40 layers of different mechanical properties from experiments quantified in Fig. 4(d), which captures the gradient structure and the corresponding variation in strength and ductility.

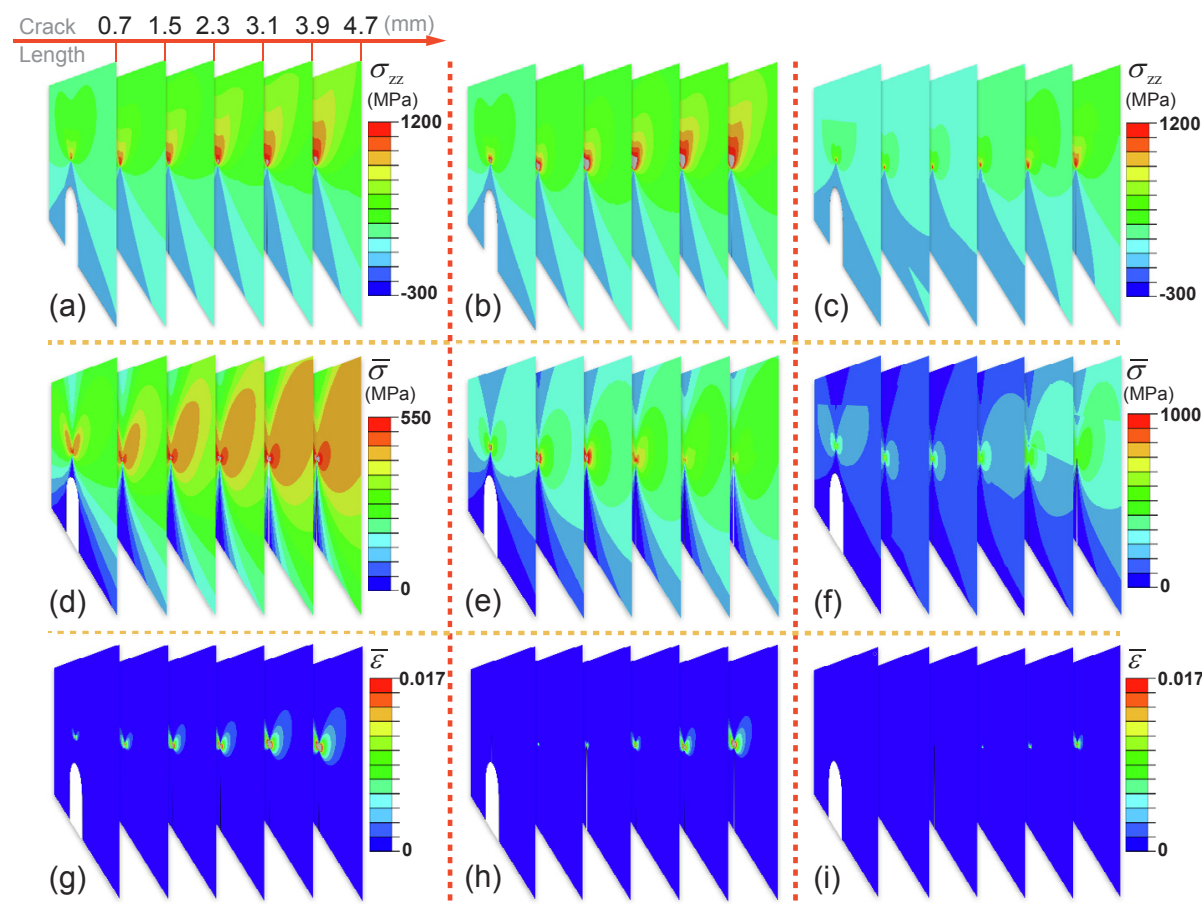

Fig. 8. The evolution of stress and strain contours in the crack-tip of the sample subject to cyclic loading with a nominal amplitude of $320 \mathrm{MPa}$ (Eqn. (4)). (a) From left to right, the principal stress $\sigma_{z z}$ in the crack tip of coarse-grained base material when the crack extends to a length of $0.7 \mathrm{~mm}$, $1.5 \mathrm{~mm}, 2.3 \mathrm{~mm}, 3.1 \mathrm{~mm}, 3.9 \mathrm{~mm}, 4.7 \mathrm{~mm}$, respectively. (b) The same type of contour from the gradient material (Fig. 7). (c) The same type of contour from the gradient material with residual stress taken into account. (d) to (f) the corresponding von Mises stress $\bar{\sigma}$ contours, and (g) to (i) the equivalent plastic strain $\bar{\varepsilon}$ contours.

gradient material. In the load-controlled fatigue test, the plastic zone of the gradient structure with compressive residual stress is obviously significantly smaller than that of the samples without residual stress distribution. The corresponding contours for the evolution process of the crack-growth with nominal stress $\sigma_{t}=480 \mathrm{MPa}$ (as shown in Fig. 9) show the similar variation with the results of nominal stress at $320 \mathrm{MPa}$ as shown in Fig. 8.

The fatigue process could be a collective resultant of stress, plastic strain, and local microstructures. In order to reflect the influence of the aforementioned factors, it was suggested that the J-integral [65-68] based on the elastic-plastic fracture mechanics can be employed to evaluate the crack-growth. For convenience, we adopted the J-integral calculation module embedded in ABAQUS to obtain the J-integral. By considering the residual stress distributions and the path independence of J-integral, the J-integral must include an additional term that accounts for the residual stress field. The total strain is decomposed into a mechanical strain $\varepsilon_{m}$ and the initial strain $\varepsilon_{i}$, i.e.

$$
\varepsilon=\varepsilon_{m}+\varepsilon_{i}
$$

The path-independence $\mathrm{J}$-integral with the residual stress field is given as:

$$
J=\int_{A} \lambda(s) \boldsymbol{N} \cdot\left(W \mathbf{I}-\sigma \cdot \frac{\partial \boldsymbol{u}}{\partial x}\right) \cdot \boldsymbol{q} d A+\int_{V} \sigma: \frac{\partial \varepsilon_{i}}{\partial x} \cdot \boldsymbol{q} d V
$$




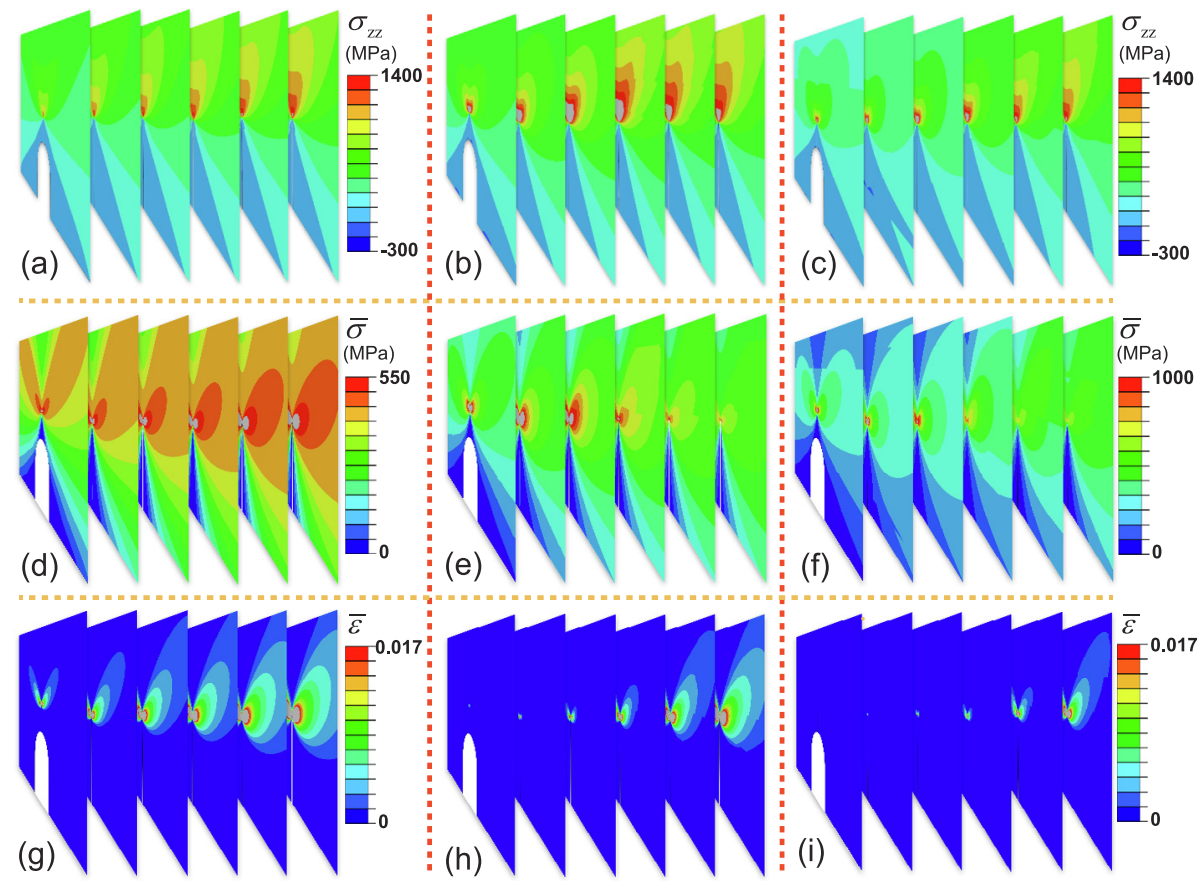

Fig. 9. The evolution of stress and strain contours in the crack-tip of the sample subject to cyclic loading with a nominal amplitude of $480 \mathrm{MPa}$ (Eqn. (4)). (a) From left to right, the principal stress $\sigma_{z z}$ in the crack tip of coarse-grained material when the crack extends to a length of $0.7 \mathrm{~mm}, 1.5 \mathrm{~mm}$, $2.3 \mathrm{~mm}, 3.1 \mathrm{~mm}, 3.9 \mathrm{~mm}, 4.7 \mathrm{~mm}$, respectively. (b) The same type of contour from the gradient material (Fig. 7). (c) The same type of contour from the gradient material with residual stress taken into account. (d) to (f) the corresponding von Mises stress $\bar{\sigma}$ contours, and (g) to (i) the equivalent plastic strain $\bar{\varepsilon}$ contours.

where $V$ is the domain volume enclosing the crack tip or crack line, and $W$ is defined as the mechanical strain energy density,

$$
W=\int_{0}^{\varepsilon_{m}} \sigma: d \varepsilon_{m}
$$

and $\varepsilon_{i}$ remains constant during the entire deformation.

We further investigated the crack-growth behaviors of train axle steel by using the J-integral. Due to the unclear mechanism of fatigue crack-growth rate in elastoplastic and general yielding conditions, the cyclic J-integral has been established as a failure criterion for fatigue problems for many years. Such an elastoplastic parameter has been successfully extended for the analysis of fatigue crack [69-73]. Here, we use the extended J-integral failure criterion by Tanaka et al. [72,73] to explore the progress of crackgrowth. For the numerical load-controlled high-cycle fatigue test, we may write the crack-growth rate as a function of $\Delta J_{\text {path }}$ :

$$
\frac{d a}{d N}=C\left(\Delta J_{p a t h}\right)^{n}
$$
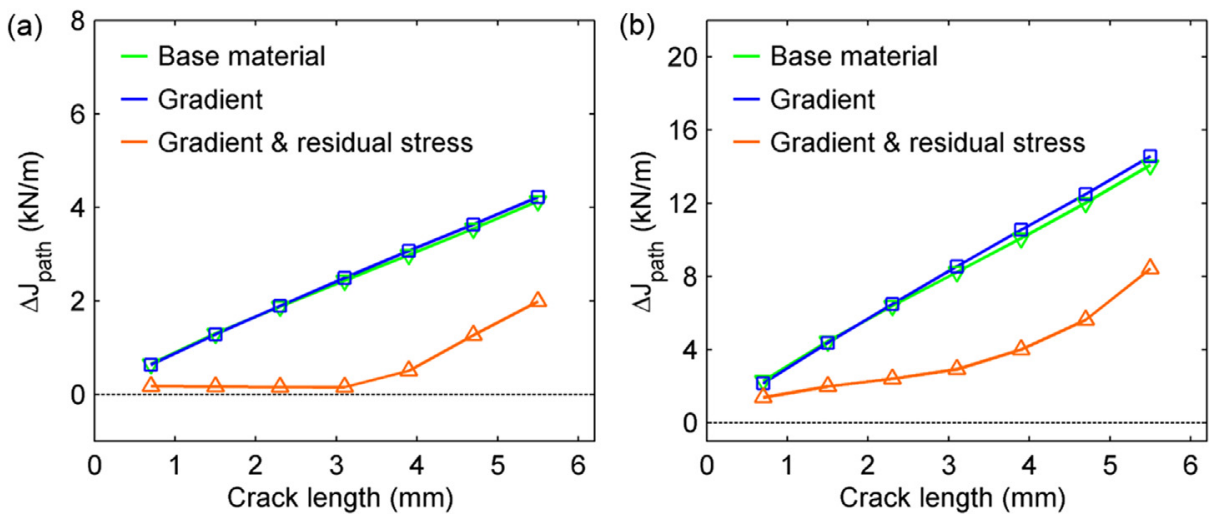

Fig. 10. A comparison of $\Delta J_{\text {path }}$ as a function of crack length among the base material, the gradient material, and the gradient material with residual stress. The applied nominal stress amplitude is (a) $320 \mathrm{MPa}$ and (b) $480 \mathrm{MPa}$, respectively. 
where $C$ and $n$ ' are material-dependent constants and $\Delta J_{\text {path }}$ is the change of the integral within a load cycle. The cyclic J-integral for small scale yielding can be determined independently and is equivalent to the value for a linear elastic crack as in the case of "monotonic" J-integral [72,73]. So the value of $\Delta J_{\text {path }}$ could be written as:

$$
\Delta J_{\text {path }}=\frac{\Delta K^{2}}{E^{*}}
$$

where $E^{*}=\frac{E}{1-v^{2}}$ for plane strain condition. Meanwhile, for plane stain problem with small scale yielding condition, the J-integral Eqn. (9) is approximately equal to that for elastic J-integral, i.e. $\Delta K=K_{\max }-K_{\min }$ with $K_{\max } \simeq \sqrt{\frac{J_{\max }}{E^{*}}}$ and $K_{\min } \simeq \sqrt{\frac{J_{\min }}{E^{*}}}$. Now the right-hand side of Eqn. (9) can be rewritten as:

$$
\Delta J_{\text {path }}=J_{\max }+J_{\min }-2 \sqrt{J_{\max } J_{\min }}
$$

where $J_{\max }$ and $J_{\min }$ are the monotonic J-integrals for the maximum applied nominal stress and the minimum applied nominal stress, respectively.

We show in Fig. 10 the curves of $\Delta J_{\text {path }}$ versus crack length under two different nominal stresses. Firstly, at both nominal stresses (as shown in Fig. 10, blue and green curves), it is observed that the $\Delta J_{\text {path }}$ values of single gradient structure are slightly higher than those of the base material. Such results above are consistent with the crack-growth behaviors of our in-situ fatigue tests and the experimental observation that introduction of a gradient structure may only slightly increase the crack growth rate [39,40] if the strength-ductility trade-off exists in the gradient layers. Based on the existence of the strength-ductility trade-off (i.e. higher strength corresponds to lower strain) in the material of different grain size, the single gradient structure has no contribution to the cyclic $\mathrm{J}$ integral. The residual stress impacts the effective stress accounting for fatigue crack growth, which reduces the magnitude of the maximum tensile stress by a significant amount. The combination of those two factors leads to the conclusion that the cyclic $\mathrm{J}$ integral is much more sensitive to residual stress distribution, other than the gradient structure. At the beginning of the crack growth (crack length about $0.7 \mathrm{~mm}$ ), short crack length and relatively low level of residual compressive stress make the $\Delta J_{\text {path }}$ of the three types of samples very close. However, with the increase of crack length and the sharp increase of compressive residual stress, the difference in $\Delta J_{\text {path }}$ becomes apparent: when the crack length increases from $0.7 \mathrm{~mm}$ to $3.1 \mathrm{~mm}$, the compressive residual stress suppresses the increase of the $\Delta J_{\text {path }}$. Due to the combined effects of gradually decreasing residual compressive stress and the gradually increasing crack length, $\Delta J_{\text {path }}$ starts to increase gradually when the crack propagates from $3.9 \mathrm{~mm}$. This variation in $\Delta J_{\text {path }}$ can be adopted to explain crack arrest at the crack length of $3 \mathrm{~mm}$ in high-cycle fatigue experiments on train axle steel [52]. Fig. 10(b) shows essentially the same trend seen in Fig. 10(a) when the nominal stress increases to $\sigma_{t}=480 \mathrm{MPa}$. The effect of residual stress on $\Delta J_{\text {path }}$ is relatively weak.

\section{Summary and conclusions}

We present in this paper a systematic investigation to illustrate the combined effects of gradient structure and residual stress on the fatigue life of train axle steel S38C. We first determined the microstructure and the distribution of residual stress of the gradient layer produced by surface induction treatment, and revealed the influence of the gradient structure on the material properties, in particular, the fatigue crack initiation and growth behavior of the gradient material. By using a finite-element model with material properties consistent with the experimental measurements, we revealed that a gradient structure could significantly alter the stress distribution near a crack tip, which could also influence the size of the local plastic zone during fatigue crack-growth. Our finiteelements simulations indicated that residual compressive stress in the gradient material could lead to a smaller local plastic zone and a more uniform stress distribution. Finally, we used the extended theory of fatigue crack growth based on cyclic J-integral to explain how the residual stress influences the crack-growth behavior and why the crack arresting occurs. All these results showed a good agreement with experimental observations. The introduced systematic mechanism investigation of gradient structure and the residual stress field could be broadly employed to enhance the fatigue life of metallic materials.

\section{Acknowledgments}

The authors acknowledge support from the National Natural Science Foundation of China (NSFC) (Grant no. 11425211), the Strategic Priority Research Program of the Chinese Academy of Sciences (XDB22020200), Key Projects in the National Science \& Technology Pillar Program during the Twelfth Five-year Plan Period (2015BAG12B01-01), National Key R\&D Program of China (2018YFB1201704-04), and Basic Scientific Research Foundation of Beijing Jiaotong University (Grant no. M14JB00130).

\section{Appendix A. Supplementary material}

Supplementary data to this article can be found online at https://doi.org/10.1016/j.engfracmech.2019.01.037.

\section{References}

[1] Bian X, Yuan F, Zhu Y, Wu X. Gradient structure produces superior dynamic shear properties. Mater Res Lett 2017:1-7.

[2] Suresh S. Fatigue of Materials. 2nd edition Cambridge University Press; 1998.

[3] Fleck NA, Kang KJ, Ashby MF. Overview No. 112: the cyclic properties of engineering materials. Acta Metall Mater 1994;42:365-81. 
[4] Cornette D, Cugy P, Hildenbrand A, Bouzekri M, Lovato G. Ultra high strength FeMn TWIP steels for automotive safety parts. Revue De Métallurgie 2005;102(12):905-18.

[5] Ray AK, Mondal S, Das SK, Ramachandrarao P. Bamboo-a functionally graded composite-correlation between microstructure and mechanical strength. J Mater Sci 2005;40(19):5249-53.

[6] Gao H, Ji B, Jager IL, Arzt E, Fratzl P. Materials become insensitive to flaws at nanoscale: lessons from nature. Proc Natl Acad Sci 2003;100(10):5597-600.

[7] Bruet BJF, Song J, Boyce MC, Ortiz C. Materials design principles of ancient fish armour. Nat Mater 2008;7(9):748-56.

[8] Lin Y, Pan J, Zhou HF, Gao HJ, Li Y. Mechanical properties and optimal grain size distribution profile of gradient grained nickel. Acta Mater 2018;153:279-89.

[9] Zerbst U, Klinger C, Klingbeil D. Structural assessment of railway axles - a critical review. Eng Failure Anal 2013;35(26):54-65.

[10] Lu K. Stabilizing nanostructures in metals using grain and twin boundary architectures. Nat Rev Mater 2016;1(5):16019.

[11] Hall EO. The deformation and ageing of mild steel: III discussion of results. Proc Phys Soc Lond B 1951;64:747-53.

[12] Petch NJ. The cleavage strength of polycrystals. J Iron Steel Inst 1953;174(1):25-8.

[13] Liu W, Wu G, Zhai C, Ding W, Korsunsky AM. Grain refinement and fatigue strengthening mechanisms in as-extruded Mg-6Zn-0.5Zr and Mg-10Gd-3Y-0.5Zr magnesium alloys by shot peening. Int J Plast 2013;49(10):16-35.

[14] Li WL, Tao NR, Lu K. Fabrication of a gradient nano-micro-structured surface layer on bulk copper by means of a surface mechanical grinding treatment. Scr Mater 2008;59(5):546-9.

[15] Lu K, Lu J. Surface nanocrystallization (SNC) of metallic materials-presentation of the concept behind a new approach. J Mater Sci Technol 1999;15(3):193-7.

[16] Wei Y, Li Y, Zhu L, Liu Y, Lei X, Wang G, et al. Evading the strength-ductility trade-off dilemma in steel through gradient hierarchical nanotwins. Nat Commun 2014;5(4):3580.

[17] Ritchie RO. The conflicts between strength and toughness. Nat Mater 2011;10(11):817.

[18] Fang TH, Li WL, Tao NR, Lu K. Revealing extraordinary intrinsic tensile plasticity in gradient nano-grained copper. Science 2011;331(6024):1587-90.

[19] Lu K. Nanomaterials. Making strong nanomaterials ductile with gradients. Science 2014;345(6203):1455-6.

[20] Chan HL, Ruan HH, Chen AY, Lu J. Optimization of the strain rate to achieve exceptional mechanical properties of 304 stainless steel using high speed ultrasonic surface mechanical attrition treatment. Acta Mater 2010;58(15):5086-96.

[21] Ma Z, Liu J, Wang G, Wang H, Wei Y, Gao H. Strength gradient enhances fatigue resistance of steels. Sci Rep-UK 2016;6:22156.

[22] Fang TH, Tao NR, Lu K. Tension-induced softening and hardening in gradient nano-grained surface layer in copper. Scr Mater 2014;77(77):17-20.

[23] Wu XL, Yang MX, Yuan FP, Chen L, Zhu YT. Combining gradient structure and TRIP effect to produce austenite stainless steel with high strength and ductility. Acta Mater 2016;112(112):337-46.

[24] Liu Y, Wei Y. Gradient driven anomalous reversible plasticity in conventional magnesium alloys. Ext Mech Lett 2016;9:158-64.

[25] Chen W, You ZS, Tao NR, Jin ZH, Lu L. Mechanically-induced grain coarsening in gradient nano-grained copper. Acta Mater 2017;125:255-64.

[26] Shao CW, Zhang P, Zhu YK, Zhang ZJ, Tian YZ, Zhang ZF. Simultaneous improvement of strength and plasticity: additional work-hardening from gradient microstructure. Acta Mater 2018;145:413-28.

[27] Zhang P, Lindemann J. Influence of shot peening on high cycle fatigue properties of the high-strength wrought magnesium alloy AZ80. Scr Mater 2005;52(6):485-90.

[28] Yang L, Tao NR, Lu K, Lu L. Enhanced fatigue resistance of Cu with a gradient nanograined surface layer. Scr Mater 2013;68(10):801-4.

[29] Roland T, Retraint D, Lu K, Lu J. Fatigue life improvement through surface nanostructuring of stainless steel by means of surface mechanical attrition treatment. Scr Mater 2006;54(11):1949-54.

[30] Huang HW, Wang ZB, Lu J, Lu K. Fatigue behaviors of AISI 316L stainless steel with a gradient nanostructured surface layer. Acta Mater 2015;87:150-60.

[31] Prabhakaran S, Kalainathan S. Compound technology of manufacturing and multiple laser peening on microstructure and fatigue life of dual-phase spring steel. Mater Sci Eng A 2016;674:634-45.

[32] Zhang YS, Han Z, Wang K, Lu K. Friction and wear behaviors of nanocrystalline surface layer of pure copper. Wear 2006;260(9):942-8.

[33] Fu T, Zhou ZF, Zhou YM, Zhu XD, Zeng QF, Wang CP, et al. Mechanical properties of DLC coating sputter deposited on surface nanocrystallized 304 stainless steel. Surf Coat Technol 2012;207(34):555-64.

[34] Wu X, Jiang P, Chen L, Yuan F, Zhu YT. Extraordinary strain hardening by gradient structure. Proc Natl Acad Sci 2014;111(20):7197-201.

[35] Ma Z, Ren Y, Li R, Wang Y, Zhou L, Wu X, et al. Cryogenic temperature toughening and strengthening due to gradient phase structure. Mater Sci Eng A 2017;712:358-64.

[36] Zeng Z, Li X, Xu D, Lu L, Gao H, Zhu T. Gradient plasticity in gradient nano-grained metals. Ext Mech Lett 2016;8:213-9.

[37] Wang Y, Yang G, Wang W, Wang X, Li Q, Wei Y. Optimal stress and deformation partition in gradient materials for better strength and tensile ductility: a numerical investigation. Sci Rep-UK 2017;7(1):10954.

[38] Tao NR, Wang ZB, Tong WP, Sui ML, Lu J, Lu K. An investigation of surface nanocrystallization mechanism in Fe induced by surface mechanical attrition treatment. Acta Mater 2002;50(18):4603-16.

[39] Yin D, Liu H, Chen Y, Yi D, Wang B, Wang B, et al. Effect of grain size on fatigue-crack growth in 2524 aluminium alloy. Int J Fatigue 2016;84:9-16.

[40] Trudel A, Lévesque M, Brochu M. Microstructural effects on the fatigue crack growth resistance of a stainless steel CA6NM weld. Eng Fract Mech 2014;115(1):60-72.

[41] Li W, Deng H, Sun Z, Zhang Z, Lu L, Sakai T. Subsurface inclusion-induced crack nucleation and growth behaviors of high strength steels under very high cycle fatigue: characterization and microstructure-based modeling. Mater Sci Eng A 2015;641:10-20.

[42] Ritchie RO, Lankford J. Small fatigue cracks: a statement of the problem and potential solutions. Mater Sci Eng 1986;84(86):11-6.

[43] Turnbull A, de Los Rios ER, Tait RB, Laurant C, Boabaid JS. Improving the fatigue crack resistance of waspaloy by shot peening. Fatigue Fract Eng Mater Struct 1998;21(12):1513-24.

[44] Altenberger I, Scholtes B, Martin U, Oettel H. Cyclic deformation and near surface microstructures of shot peened or deep rolled austenitic stainless steel AISI 304. Mater Sc Eng A 1999;264(1-2):1-16.

[45] Xu T, Feng Y, Song S, Wang D. Fatigue crack propagation behaviour of steels with different microstructures. Mater Sci Eng A 2012;551(8):110-5.

[46] Ye C, Telang A, Gill AS, Suslov S, Idell Y, Zweiacker K, et al. Gradient nanostructure and residual stresses induced by ultrasonic nano-crystal surface modification in 304 austenitic stainless steel for high strength and high ductility. Mater Sci Eng A 2014;613(11-12):274-88.

[47] Salvati E, Zhang H, Fong KS, Song X, Korsunsky AM. Separating plasticity-induced closure and residual stress contributions to fatigue crack retardation following an overload. J Mech Phys Solids 2017;98:222-35.

[48] Gu P, Asaro RJ. Crack deflection in functionally graded materials. Int J Solids Struct 1997;34(24):3085-98.

[49] Tilbrook MT, Moon RJ, Hoffman M. Crack propagation in graded composites. Compos Sci Technol 2005;65(2):201-20.

[50] Li S, Kang Y, Kuang S. Effects of microstructure on fatigue crack growth behavior in cold-rolled dual phase steels. Mater Sci Eng A 2014;612(9):153-61.

[51] Martelo DF, Mateo A, Chapetti MD. Crack closure and fatigue crack growth near threshold of a metastable austenitic stainless steel. Int J Fatigue 2015;77:64-77.

[52] Zhang S, Xie J, Jiang Q, Zhang X, Sun C, Hong Y. Fatigue crack growth behavior in gradient microstructure of hardened surface layer for an axle steel. Mater Sci Eng A 2017;700:66-74.

[53] Paris PC, Gomez MP, Anderson WE. A rational analytic theory of fatigue. Trend Eng 1961;13:9-14.

[54] Paris PC, Erdogan F. A critical analysis of crack propagation laws. Trans. ASME 1963;85(4):528-33.

[55] Ramberg W, Osgood WR. Description of stress-strain curves by three parameters. Tech Note 1943;902.

[56] Gurson AL. Continuum theory of ductile rupture by void nucleation and growth: part 1-yield criteria and flow rules for porous ductile media. J Eng Mater Technol 1975;99(1):297-300.

[57] Tvergaard V. Influence of voids on shear band instabilities under plane strain conditions. Int J Fract 1981;17:389-407.

[58] Tvergaard V. On localization in ductile materials containing spherical voids. Int J Fract 1982;18:237-52.

[59] Tvergaard V, Needleman A. Analysis of the cup-cone fracture in a round tensile bar. Acta Metall 1984;32:157-69. 
[60] Chu CC, Needleman A. Void nucleation effects in biaxially stretched sheets. J Eng Mater Technol 1980;102(3):249-56.

[61] Abaqus FEA, D.S.S.D. Systèmes, Editor 2007; 2007.

[62] Wang Y, Yang G, Lei X, Li Q, Rong L, Hu X, et al. Metal ductility evaluation by flattening test: the geometry dependence. Int J Pres Ves Pip 2019;170:40-8.

[63] Altenbach H, Öchsner A. Plasticity of Pressure-Sensitive Materials. Berlin Heidelberg: Springer; 2014.

[64] Fajkoš R, Zima R, Strnadel B. Fatigue limit of induction hardened railway axles. Fatigue Fract Eng Mater Struct 2015;38(10):1255-64.

[65] Cherepanov GP. Crack propagation in continuous media. J Appl Math Mech 1967;31(31):503-12.

[66] Rice JR. A path independent integral and the approximate analysis of strain concentration by notches and cracks. J Appl Mech 1968;35(2):379-86.

[67] Jiang Y, Ott W, Baum C, Vormwald M, Nowack H. Fatigue life predictions by integrating EVICD fatigue damage model and an advanced cyclic plasticity theory. Int J Plast 2009;25(5):780-801.

[68] Ding F, Feng M, Jiang Y. Modeling of fatigue crack growth from a notch. Int J Plast 2007;23(7):1167-88.

[69] Dowling NE, Begley JA. Fatigue crack growth during gross plasticity and the J-integral. Mechanics of Crack Growth, ASTM Special Technical Publication 590. 1976.

[70] Dowling NE. Crack growth during low-cycle fatigue of smooth axial specimens. ASTM Spec Tech Public $1977 ; 637$.

[71] Dowling NE, Iyyer NS. Fatigue crack growth and closure at high cyclic strains. Mater Sci Eng 1987;96(12):99-107.

[72] Tanaka K. The cyclic J -integral as a criterion for fatigue crack growth. Int J Fract 1983;22(2):91-104.

[73] Tanaka K, Akiniwa Y, Shimizu K. Propagation and closure of small cracks in SiC particulate reinforced aluminum alloy in high cycle and low cycle fatigue. Eng Fract Mech 1996;55(5):751-62. 